\title{
INFLUÊNCIA DO ESPAÇAMENTO E IDADE DA BROTAÇÃO NA MORFOMETRIA DE POVOAMENTOS DE Ilex paraguariensis St. Hill. ${ }^{1}$
}

\section{EFFECTS OF SPACEMENT AND SHOOT AGE ON MORPHOMETRY OF Ilex paraguariensis St. Hill. STANDS}

\author{
Frederico Dimas Fleig ${ }^{2}$ Paulo Renato Schneider ${ }^{3}$ César Augusto Guimarães Finger ${ }^{4}$ \\ RESUMO
}

Este trabalho apresenta aspectos da morfometria de erveiras reflorestadas. A área de estudos localiza-se no estado de Santa Catarina, no município de Catanduvas. As plantas avaliadas apresentam idade aproximada de 14 anos, e estão dispostas em um arranjo fatorial com espaçamentos de 3, 4 e $5 \mathrm{~m}$ nas entrelinhas e 2, 3 e $4 \mathrm{~m}$ nas linhas. Dividiram-se as erveiras em dois grupos, sendo o primeiro podado em setembro, e o segundo, em janeiro respectivamente, quando as copas atingiram 24 e 28 meses de idade. A totalidade das erveiras avaliadas apresentam-se bifurcadas na proximidade da base, assim, o perímetro ao nível do solo apresenta-se com correlação não-significativa com a biomassa da copa. Pela comparação das áreas basais e número de troncos obtidos a 0,3,06 e 0,9 $\mathrm{m}$ de altura, constatou-se que a altura ideal de avaliação do tronco é a $0,60 \mathrm{~m}$ de altura em relação ao nível do solo. A área basal por planta, a essa altura, foi positivamente influenciada pelos espaçamentos nas entrelinhas e nas linhas (Prob<0,05). O número de troncos à altura de $0,6 \mathrm{~m}(\mathrm{Nt} 6)$ da planta foi significativamente influenciado pela distância entre plantas na linha, na qual a de $2 \mathrm{~m}$ foi menor e divergente das demais. Os espaçamentos entre erveiras influenciaram as dimensões das copas, sendo o diâmetro da copa (Dc8) significativamente influenciado pelo espaçamento nas linhas, com superioridade para os maiores espaçamentos. O comprimento da copa (Cc) e a altura total (ht) foram significativamente influenciados pelas distâncias na linha e na entrelinha. $\mathrm{O}$ grau de copa $(\mathrm{Cc} / \mathrm{ht})$ só apresenta diferença significativa para o fator linha. Já o grau de cobertura (Dc8/ht) apresentou diferença significativa para o fator distância entrelinhas. O formal de copa $(\mathrm{Dc} 8 / \mathrm{Cc})$ atingiu valores próximos à unidade, pois as erveiras apresentam copas com diâmetro proporcional ao seu comprimento.

Palavras-chave: erva-mate, reflorestamento, biometria, copa, poda.

\section{ABSTRACT}

This work shows morphometric characteristics of Ilex paraguariensis St. Hil. pruned under reforestation. The study was carried out in Catanduvas, Santa Catarina State. All trees (about 14 years old) were cultivated in soil with similar characteristics. The experiment followed a randomized block design arranged in a factorial $3 \times 3$ corresponding to three distances between the rows of trees $(3,4$, and $5 \mathrm{~m})$ and three distances between trees within the rows $(2,3$, and $4 \mathrm{~m})$. The trees were divided into two groups. Each group was pruned in September or in January, when the crown was 24 or 28 months old, respectively. All trees were bifurcated near the ground, and, therefore, the perimeter at this level did not show a significant correlation with the crown biomass. The comparison of basal area and number of trunks per plant at the highs of $0.3,0.6$, and $0.9 \mathrm{~m}$, showed that the ideal position to evaluate the trunk attributes was $0.60 \mathrm{~m}$ above the ground. The basal area of the trees at this position (g6) reduced with the reduction of the distance between the rows and between the trees within the rows $(\mathrm{P}<0.05)$. The number of trunks per plant measured at $0.6 \mathrm{~m}$ above the ground (Nt6) was significantly affected by the distance between plants within the row, with the lowest value been observed when the distance between plants was $2 \mathrm{~m}$. The crown diameter of the trees (Dc8) was higher on trees cultivated under higher spacing between the rows. Crown

1. Parte da Tese de Doutorado apresentada pelo primeiro autor para obtenção do título de Doutor em Engenharia Florestal, pelo Programa de Pós-graduação em Engenharia Florestal, da Universidade Federal de Santa Maria, CEP 97105-900, Santa Maria (RS)

2. Engenheiro Florestal, Dr., Professor do Departamento de Fitotecnia, Centro de Ciências Agroveterinárias, Universidade do Estado de Santa Catarina, CEP 88520-000, Lages (SC). a2fdf@ cav.udesc.br

3. Engenheiro Florestal, Dr., Professor Titular do Departamento de Ciências Florestais, Centro de Ciências Rurais, Universidade Federal de Santa Maria, CEP 97105-900, Santa Maria (RS). paulors@ @cr.ufsm.br

4. Engenheiro Florestal, Dr., Professor Adjunto do Departamento de Ciências Florestais, Centro de Ciências Rurais, Universidade Federal de Santa Maria, CEP 97105-900, Santa Maria (RS). finger@ ccr.ufsm.br

Recebido para publicação em 11/12/2002 e aceito em 19/05/2003. 
length and the total high of the trees (ht) were significantly affected by the distance between the rows and by the distance between the trees within the rows. Crown ratio $(\mathrm{Cc} / \mathrm{ht})$ was only affected by the distance between plants within the rows. The degree of coverage (Dc8/ht) was affected by the distance between rows. The crown shape $(\mathrm{Dc} 8 / \mathrm{Cc})$ values were close to unity, since the trees showed crown diameter proportional to the crown length.

Key words: erva-mate, reforestation, biometrics, crown, pruning.

\section{INTRODUÇÃO}

No sul do Brasil, a erva-mate é importante fonte de renda para um número expressivo de produtores rurais. Sua produção ocorre tanto em pequenas como em grandes propriedades rurais, constituindo-se normalmente em uma das múltiplas atividades produtivas.

A colheita da erva-mate tem como característica básica a remoção dos galhos e ramos para o aproveitamento das folhas e ramos finos que são amplamente utilizados na indústria para produção de diversas bebidas, destacando-se o chimarrão. A colheita, no Brasil, é executada manualmente com auxílio de tesouras, facão ou foice.

As recomendações para plantio de erva-mate baseiam-se no sistema de produção adotado. Quando em monocultivo, os espaçamentos são mais reduzidos. Prat Kricun e Belingheri (1992) recomendaram 2,25 x 1m. Em sistemas agrosilviculturais, os espaçamentos são maiores, chegando a 6 x 4m ou 8 x 3m. Segundo Schneider e Petry (1985), independente do espaçamento, cada árvore, nesse sistema, produz aproximadamente $15 \mathrm{~kg}$ de biomassa comercial por colheita bianual.

Os tratamentos dispensados à planta de erva-mate na colheita têm reflexos diretos no rendimento da cultura nas próximas colheitas. Munareto (1992) recomendou cortar, quando possível, somente os ramos maduros, porque brotam melhor e produzem bom material de corte. O corte dos brotos jovens provoca a formação de ramos de baixa capacidade produtiva.

Segundo a teoria da autonomia dos ramos, a copa das árvores pode ser considerada como uma população de ramos. Assim, o nascimento, crescimento e morte, ou desrama natural definem a estrutura da copa para uma árvore em particular. $\mathrm{O}$ desenvolvimento dos ramos depende de alguns processos ecofisiológicos, como a condição de luminosidade na copa, da água e nutrientes alocados para o ramo. Além disso, o crescimento dos ramos é controlado por interação hormonal entre o tronco e os ramos (Mäkinen, 1999).

As diferenças na forma entre uma árvore e outra podem ter suas bases causais explicadas pela engenharia estrutural que visualiza a árvore por causa da forma dos ramos, sua elasticidade e resistência para esforço, como unidades estruturais restritas por bem conhecidos princípios mecânicos (Porter, 1989). Nesse sentido, Mattheck (1991) observou que o design da árvore deve necessariamente ser conciliador, ou seja, é resultado de um acordo equilibrado. Uma copa larga, embora seja boa fotoreceptora, é pesada e alguns membros de suporte (tronco e ramos) são requeridos e, assim, eles devem desenvolver-se, manter e, se necessário for, repor-se. O melhor design possível de uma árvore deve necessariamente minimizar o material utilizado. Copas largas perdem muita água pela transpiração. A água evaporada deve ser reposta por quantidade suficiente de novos suprimentos transportados até os brotos por um sistema de raízes equivalente com os brotos. Copas largas são muito sujeitas a danos por vento. O tronco deve ser muito resistente ao arqueamento, e o sistema de raízes deve estar muito bem ancorado para resistir à carga dos ventos, meios que requerem a imobilização de muito material com suficiente resistência tanto no desenvolvimento como na manutenção. Todos esses requerimentos neutralizadores resultam na ideal compromise tree, caracterizada pela maior copa possível, porém, com o menor número de membros de suporte, todos com suficiente resistência, mas não tão grande que adicione peso e aumente a energia consumida.

Para a caracterização morfométrica de copas de Cabralea canjerana, Durlo e Denardi (1998) utilizaram o comprimento de copa, o diâmetro de copa, a altura da inserção da copa, a proporção de copa, o índice de saliência, o índice de abrangência e o formal de copa. Deve-se salientar que essas variáveis

Ciência Florestal, v. 13, n. 1, 2003 
baseiam-se no modelo de árvore desenvolvido por Bürger e por Badoux, apud Assmann (1970), em que as copas são classificadas em função do formal de copa, que é a razão do diâmetro médio da copa com o comprimento total dessa copa, em magras, médias e cheias respectivamente para valores próximos de $0,4 \mathrm{em}$ torno de 0,5 e superiores a 0,6 .

O diâmetro tomado a $0,50 \mathrm{~m}$ de altura do nível do solo foi comparado por Canadell et al. (1988) com a altura de 1,30 m (DAP) na estimativa da biomassa acima do solo de árvores de Quercus ilex, sendo constatado que, em razão da maior uniformidade do tronco a $0,50 \mathrm{~m}$, as funções que utilizam essa variável foram mais precisas. Dean e Long (1986) utilizaram o diâmetro do tronco à altura de 1,30 m para árvores maduras e 0,25 $\mathrm{m}$ da base para arvoretas de sub-bosque para estudar as variações na relação área do alburno/área foliar entre dois povoamentos de Pinus contorta Dougl. Nesse mesmo sentido, O'Connell e Kelty (1994) utilizaram o diâmetro do tronco a 0,30 m acima do colar de raízes para estudar a arquitetura de copas de plantas de Pinus strobus L. que apresentavam altura total de $2 \mathrm{~m}$. Whittaker e Woodwell (1968) propuseram o diâmetro a 1,30 m para árvores e a 0,10 $\mathrm{m}$ de altura para arbustos.

O diâmetro à altura do peito (DAP) em erva-mate, por causa dos procedimentos de poda, é impraticável pela quantidade de troncos. Para superar essa dificuldade, Fossati (1997) utilizou a circunferência à altura da base do tronco que foi convertido para diâmetro. Crow e Laidly (1980) utilizaram para Ilex verticillata (L.) Gray o diâmetro ao nível do solo, pois as plantas apresentavam menos de três metros de altura e as menores não atingiam o DAP.

Nos últimos anos, grande parte dos ervais foram instalados com espaçamentos reduzidos, contendo até quatro mil plantas por hectare. Nesses ervais, a colheita deve ser anual para limitar o crescimento apical, mas as folhas produzem erva-mate para chimarrão com sabor muito amargo. Conseqüentemente, o produto sem misturas com erva-mate de ervais nativos manejados, e que sofrem poda em intervalos não-inferiores a 36 meses, apresentam limitações comerciais (informação pessoal de industriais do mate de Catanduvas $\mathrm{SC})$.

Apesar da importância econômica, social e cultural da erva-mate, existem poucas informações publicadas a respeito de sua morfometria.

No presente trabalho de pesquisa, pretendeu-se alcançar os seguintes objetivos:

a) Determinar a altura ideal para avaliação do diâmetro do tronco que proporcione boa estimativa da produção de biomassa.

b) Avaliar a área basal, o número de troncos e a morfometria da copa das erveiras, aos 24 e 28 meses após a poda, em diferentes espaçamentos e sítios similares.

\section{MATERIAL E MÉTODOS}

\section{Caracterização do local}

A área de estudos localiza-se na região centro-oeste do estado de Santa Catarina, no município de Catanduvas, no Km 3 da estrada para Vera Cruz. O município está situado, aproximadamente, em $27^{\circ} 04^{\prime}$ de latitude sul e $51^{\circ} 40^{\prime}$ de longitude oeste.

A vegetação original era de matas mistas com araucária, canelas e outras espécies, ricas em erva-mate, que foram parcialmente removidas para o cultivo de espécies anuais e pastagens e, mais recentemente, foram parcialmente convertidas em ervais.

Segundo Leite e Klein (1990), a vegetação da região é classificada como Floresta Ombrófila Mista cujas formações secundárias são caracterizadas na região pela presença maciça da bracatinga ( Mimosa scabrella), canela-guaicá (Ocotea puberula), vassourão-branco (Piptocarpa angustifolia), vassourão-preto (Vernonia discolor), angico-branco (Anadenanthera colubrina), café-do-mato (Casearia sylvestris), vassourais (Baccharis spp.) e samambaia-das-taperas (Pteridium aquinum).

A altitude é de aproximadamente 1.000 metros acima do nível médio do mar (Santa Catarina, 1986). A área de estudos está localizada sobre o cume de uma elevação, ou divisor de águas, ocupando os quadrantes norte, leste e sul.

Ciência Florestal, v. 13, n. 1, 2003 
A edafologia local é variada, com predominância dos solos do tipo bruno ácidos. Na classificação feita por Santa Catarina (1986), os solos do local de estudos enquadram-se na definição da terra bruna estruturada húmica álica mais cambissolo bruno húmico álico de textura argilosa e muito argilosa, com face pedregosa e não-pedregosa, o TBHa2.

O clima da região é, segundo a classificação de Köppen, do tipo "cfb", mesotérmico, subtropical úmido, sendo seus verões frescos, com temperatura média anual de $16^{\circ} \mathrm{C}$, não apresentando estação seca definida, sendo a precipitação média anual próxima de $2.000 \mathrm{~mm}$, apresentando geadas freqüientes, em média mais de quinze por ano (Mota et al., 1971).

\section{Características da população de erva-mate}

O erval foi implantado em outubro de 1985, em solo subsolado e gradeado. As covas de plantio foram adubadas com $2 \mathrm{~kg}$ de cama de aviário. Esse erval foi conduzido com interplantios de soja ou milho de 1985 até 1991, pois era experimento de agrossilvicultura da EPAGRI, segundo informações dos proprietários dos ervais.

O plantio obedeceu a diferentes espaçamentos, com 3, 4 e $5 \mathrm{~m}$ nas entrelinhas e 2, 3 e $4 \mathrm{~m}$ na linha, constituindo respectivamente os fatores e os níveis, totalizando nove tratamentos que foram aleatorizados em cinco blocos, primeiramente em função da entrelinha e depois da linha.

Cada tratamento foi constituído de 28 plantas, dispostas em quatro linhas de sete plantas, sendo que as plantas das linhas externas e das extremidades das linhas centrais, constituem a bordadura, totalizando dez plantas úteis por tratamento.

A primeira colheita foi realizada em 1988, e até 1991 eram anuais. A partir de 1991, as podas foram realizadas a cada dois anos, sendo que a última foi realizada em agosto-setembro de 1997.

Para possibilitar a comparação entre árvores com idade de brotação de 24 e 28 meses, foram realizadas podas no período de repouso vegetativo (setembro) e no período de frutificação (janeiro). Em cada período, foram avaliados dois blocos, totalizando 180 plantas por ocasião. Para seleção dos blocos que seriam avaliados em cada ocasião, utilizaram-se a classificação visual das copas e a integridade dos blocos. O bloco 1, por apresentar elevado número de falhas em alguns tratamentos, foi escolhido para a pesquisa preliminar. Como as plantas dos blocos 2 e 4 apresentavam nitidamente copas menores que as dos blocos $3 \mathrm{e}$ 5 , intencionalmente e especialmente porque estavam próximos, escolheram-se os blocos 2 e 3 para serem podados, quando as brotações atingissem, aproximadamente, 24 meses de idade, e os blocos 4 e 5, quando as brotações atingissem idade aproximada de 28 meses.

\section{Instalação e condução dos experimentos}

\section{Altura de medição do diâmetro do tronco}

As árvores do bloco 1 foram avaliadas dendrométrica e qualitativamente para uma definição precisa das variáveis avaliadas e das metodologias utilizadas nos demais blocos. Após essa avaliação, as árvores foram podadas (remoção total da brotação) e sua biomassa fracionada.

Variáveis dendrométricas e instrumentos utilizados para avaliação das árvores da pesquisa preliminar:

a) ht - Altura total da erveira (m): corresponde à distância do solo até a altura média dos brotos mais altos, medida com régua de $3 \mathrm{~m}$, com precisão de $0,1 \mathrm{~m}$.

b) hic - Altura do início da copa $(\mathrm{m})$ : medida com régua de $1,5 \mathrm{~m}$, com precisão de $0,1 \mathrm{~m}$. Essa variável foi avaliada considerando a distância média existente entre o solo e o início da copa.

c) Dmc - Diâmetro médio da copa (m): medição de 8 raios com ângulos entre si de $45^{\circ}$, marcados com precisão de $0,1 \mathrm{~m}$ sobre duas lonas plásticas que eram estendidas abaixo da erveira. Os raios eram determinados com auxílio de um bastão que, ao ser suspenso pela extremidade superior, funciona como um pêndulo.

d) g0 - Área da base do tronco $\left(\mathrm{m}^{2}\right)$ : determinada pela conversão do perímetro tomado a 0,0 m de 
altura, com auxílio de fita métrica e precisão de $0,01 \mathrm{~m}$.

e) g3, g6 e g9 - Áreas basais dos troncos de uma planta para alturas de 0,3 m; 0,6 m e 0,9 metros $\left(\mathrm{em} \mathrm{m}^{2}\right)$ : determinados pela conversão dos diâmetros dos troncos a 0,3, 0,6 e 0,9 $\mathrm{m}$ de altura, obtidos com precisão de $0,001 \mathrm{~m}$, com auxílio de paquímetro.

f) Nt3, Nt6 e Nt9 - Número de troncos com mais de $0,01 \mathrm{~m}$ de diâmetro a $0,3 \mathrm{~m} ; 0,6 \mathrm{~m}$ e $0,9 \mathrm{~m}$. Obtido pela contagem do número de registros para obtenção de g3, g6 e g9.

g) BC - Peso verde da biomassa comercial (kg): peso verde das frações constituídas de ramos finos, brotos e folhas, determinado com precisão de $0,001 \mathrm{~kg}$, com auxílio de balança digital de $6 \mathrm{~kg}$ de capacidade de carga.

h) PM - Peso verde da madeira de brotação (kg): peso verde dos resíduos de madeira com idade da brotação. Determinado com precisão de $0,001 \mathrm{~kg}$, com auxílio de balança digital de $6 \mathrm{~kg}$ de capacidade de carga.

\section{Efeitos da idade da brotação e do espaçamento entre plantas}

Após a definição da altura de medição dos troncos, optou-se por avaliar, nos quatro blocos restantes, as seguintes variáveis:

a) ht - Altura total da erveira (m): corresponde à distância do solo até a altura média dos brotos mais altos, medida com régua de 3 metros, com precisão de $0,1 \mathrm{~m}$.

b) hi - Altura do início da copa (m): essa avaliação foi realizada concomitante com a medição dos oito raios das copas, pois a régua graduada que servia de prumo para a determinação da expansão horizontal da copa permitia a determinação da altura em que iniciava a massa de folhas em cada um dos oito raios. Utilizou-se régua de 3 metros, com precisão de $0,1 \mathrm{~m}$. A variável é representada pela média aritmética das oito alturas determinadas.

c) Dc8 - Diâmetro médio da copa $(\mathrm{m})$ : obtido pela divisão por quatro da soma dos oito raios $\left(\mathrm{r}_{\mathrm{i}}\right)$ com ângulos entre si de $45^{\circ}$. Para determinação acurada dos raios e ângulos, utilizou-se um gabarito desmontável, com sistema de encaixe macho-fêmea, confeccionado com tubos de aço de seção quadrada, com bitolas de 15 e $20 \mathrm{~mm}$ (Figura 1). A menor bitola foi utilizada para confecção das réguas graduadas para determinação dos raios e a maior, para a estrutura com encaixes em que são inseridas as réguas removíveis. Os raios foram determinados com auxílio de um bastão que, ao ser suspenso pela extremidade superior, funcionou como prumo indicando assim, na régua graduada do gabarito, a distância do centro do gabarito que corresponde, de fato, ao centro da árvore até o limite horizontal da copa naquele raio.

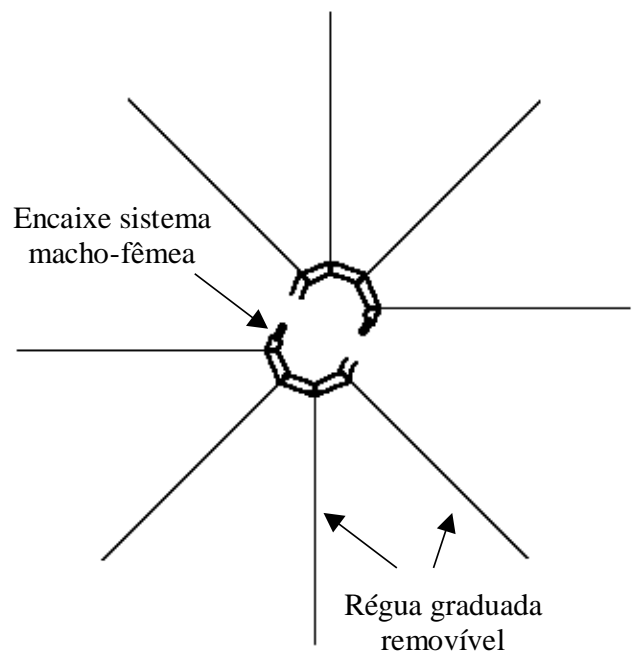

FIGURA 1: Gabarito construído para determinação dos raios da copa.

FIGURE 1: System designed to assess crown radius. 
d) Nt6 - Número de troncos com mais de 0,01m de diâmetro à altura de 0,6 metros do solo: obtido pela contagem do número de registros de diâmetro do tronco de cada erveira.

e) g6 - Área basal do tronco $\left(\mathrm{m}^{2}\right)$ : corresponde ao somatório das áreas basais dos troncos de uma planta, determinados pela conversão dos diâmetros dos troncos a $0,6 \mathrm{~m}$ de altura (d6) com auxílio da função g6 $=\sum\left(\mathrm{d} 6^{2}\right.$. 0,7854). Os diâmetros foram obtidos com precisão de $0,001 \mathrm{~m}$, com auxílio de paquímetro.

Com base nas determinações de ht e hi foi calculada a seguinte variável:

f) Cc - Comprimento da copa: é a diferença entre as alturas total (ht) e início da copa (hi), ou seja, $\mathrm{Cc}=\mathrm{ht}-\mathrm{hi}$.

Adicionalmente, com base nas variáveis Dc8, ht e Cc, foram calculadas as seguintes razões:

g) Dc8/ht - Grau de cobertura: é a razão entre o diâmetro médio da copa (Dc8) e a altura total da erveira (ht).

h) Dc8/Cc - Formal de copa: é a razão entre o diâmetro médio da copa (Dc8) e o comprimento da copa $(\mathrm{Cc})$.

i) Cc/ht - Grau de copa: é a razão entre o comprimento de copa (Cc) e a altura total (ht).

j) Ac/g6 - Índice de espaço vital: é a razão entre a área da copa (Ac) e a área basal do tronco (g6), onde $\mathrm{Ac}=\mathrm{Dc} 8^{2}$. 0,7854.

O modelo de árvore desenvolvido por Bürger e Badoux e apresentado por Assmann (1970) foi adaptado para as características das erveiras avaliadas e está representado na Figura 2. Esse modelo permite visualizar algumas características dessas plantas, como a altura dos troncos após a poda e o ponto de medição dos diâmetros dos troncos, das alturas avaliadas nas copas e da representação do diâmetro médio da copa representado pela variável Dc8.

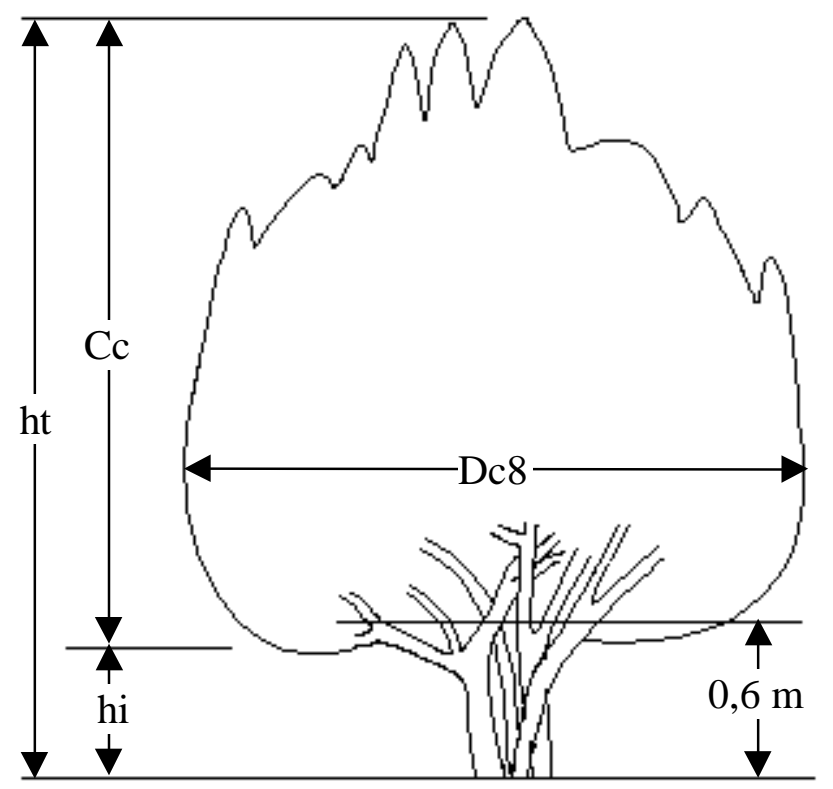

FIGURA 2: Modelo de erveira com suas características dimensionais.

FIGURE 2: Model of an Ilex paraguariensis tree with its dimensional characteristics.

\section{Processamento dos dados}

Com base nos dados coletados, foram calculados a área basal (g6), o número de troncos (Nt6), o diâmetro médio de copa (Dc8) e a altura de início da copa (hi). Essas variáveis, mais a altura total (ht), o número do bloco, as distâncias nas entrelinhas e nas linhas, o índice de frutificação (IF), o fator de copa (Fc) e os pesos da biomassa comercial (BC) e residual (PM) formaram o banco básico de dados utilizado para a confecção de gráficos e de planilhas que foram analisadas estatisticamente por meio do processamento dos 
Influência do espaçamento e idade da brotação na morfometria de povoamentos de Ilex paraguariensis ... 79

dados pelo pacote "SPSS for Windows", versão 7.5.1 (SPSS, 1996).

Os dados de g6, Nt6, Dc8, ht, Cc, Cc/ht, Dc8/ht, Dc8/Cc e Ac/g6 das árvores podadas nos blocos 2 e 3, quando apresentavam copa com 24 meses de idade, e dos blocos 4 e 5, podados aos 28 meses, foram submetidos à análise de variância a fim de verificar a existência de diferenças de médias para os fatores blocos, idade, distância da entrelinha e na linha, pelo teste LSD, Prob. $=5 \%$.

\section{RESULTADOS E DISCUSSÕES}

\section{Diâmetro médio da copa ou raio médio da copa}

Para uma determinação precisa da área transversal ocupada pela copa, a literatura indica a medição de oito raios com ângulos de $45^{\circ}$ entre si. Como as copas das erveiras raramente ultrapassam três metros de diâmetro e apresentam pequena altura em relação ao solo, a determinação dos ângulos dos raios com precisão é difícil. Na tentativa de solucionar esse problema, testou-se, na avaliação preliminar, o uso de duas lonas de náilon de 2 × 3 metros, sobre as quais se marcaram quatro raios graduados em intervalos de 0,1 metro. Essas lonas foram estendidas sobre o solo, uma de cada lado da árvore, formando assim os oito raios com origem na base da árvore. O uso desse método, contudo, apresentou severas limitações quando o solo apresentava rugosidade ou havia a presença de plantas altas nas entrelinhas, o que dificultava a instalação das lonas e, conseqüentemente, a confiabilidade das avaliações. Como solução para esse problema, desenvolveu-se a ferramenta descrita em "material e métodos" (Figura 1) e utilizada neste trabalho.

A altura de início da copa pode ser estimada definindo-se visualmente a altura média e determinando a distância desse ponto até o solo com régua graduada em 0,10 metros. A maior dificuldade desse método é definir com precisão o ponto em que essa altura é média. Com a nova ferramenta, essa limitação poderá ser superada pela determinação das alturas de início da copa em cada um dos oito raios medidos para obtenção do diâmetro médio de copa.

\section{Altura de medição do diâmetro dos troncos}

Segundo a literatura, a altura de avaliação do diâmetro do tronco varia entre a medição ao nível do solo ou $0,0 \mathrm{~m}$ até $1,30 \mathrm{~m}$ de altura, que corresponde ao DAP (diâmetro à altura do peito).

As avaliações do diâmetro em erveiras plantadas aos níveis superiores ao do solo mostram números crescentes de troncos, como pode ser observado na Tabela 1, na qual as diferenças entre o número de troncos tomados a 0,3; 0,6 e 0,9 m de altura foram altamente significativas, sendo o número médio de troncos avaliados, respectivamente, 5,7; 8,7 e 13,4 troncos. Esse aumento no número de troncos em alturas superiores era esperado, pois se pode considerar as erveiras conduzidas com ramos ou bifurcações ao nível do solo como sendo indivíduos com múltiplos troncos ou como árvores desprovidas de tronco por efeito de poda, em que os ramos de suas copas, de onde se originam as novas brotações, são considerados troncos e essas brotações são seus ramos.

TABELA 1: Estatísticas básicas e comparação de médias do número de troncos a 0,3;0,6 e 0,9 metros de altura de erveiras (avaliação preliminar de 70 árvores).

TABLE 1: Statistical analysis and average comparison test for number of trunks at the heights of $0.3,0.6$, and $0.9 \mathrm{~m}$ of $I$. Paraguariensis trees (preliminary evaluation of 70 trees).

\begin{tabular}{|c|c|c|c|c|c|}
\hline \multirow[t]{2}{*}{ Variáveis } & \multirow[t]{2}{*}{ Média } & \multicolumn{2}{|c|}{ Erro Padrão } & \multirow{2}{*}{\multicolumn{2}{|c|}{$\begin{array}{l}\text { Intervalo de Confiança para a média } \\
\text { (Prob. }<0,05)\end{array}$}} \\
\hline & & Interno & Ponderado & & \\
\hline NT3 & $5,70 \mathrm{a}$ & 0,2367 & 0,4276 & 4,86 & 6,54 \\
\hline NT6 & $8,71 \mathrm{~b}$ & 0,3406 & 0,4276 & 7,87 & 9,56 \\
\hline NT9 & $13,37 \mathrm{c}$ & 0,6136 & 0,4276 & 12,53 & 14,21 \\
\hline Total & 9,26 & 0,2469 & 0,2469 & 8,76 & 9,75 \\
\hline $\mathrm{F}^{1}$ & 81,698 & - & - & - & - \\
\hline
\end{tabular}

Em que: Médias seguidas da mesma letra, não diferem entre si, ao nível de $1 \%$ de probabilidade pelo teste LSD; $1=$ Significativo (Prob. < 0,00001); Nt3 = Número de troncos a 0,3 $\mathrm{m}$ de altura do solo; $\mathrm{Nt} 6=$ Número de troncos a $0,6 \mathrm{~m}$; $\mathrm{Nt} 9=$ Número de troncos a 0,9 m; F = Estatística razão F.

As copas de erveiras formadas de múltiplos troncos, em níveis próximos ao solo, dificultam a 
realização da medição do perímetro a esse nível pela necessidade de remoção da vegetação que cresce próxima à base do tronco, bem como pela existência de formigueiros, ou mesmo o risco da presença de ofídios nos meses mais quentes do ano, o que desestimula a avaliação nessa altura. Contudo, tal avaliação é mais rápida que as executadas a alturas superiores por ser realizada considerando o perímetro de um único tronco.

As avaliações de diâmetro do tronco, realizadas acima de 0,3 metros de altura, apresentam um aumento de, aproximadamente, 53 e $135 \%$ no número de troncos avaliados, respectivamente, para 0,6 e 0,9 metros de altura. Esse incremento no número de troncos requer mais tempo para medição e dificulta o controle da avaliação. Como as copas das erveiras conduzidas com múltiplos troncos e brotações com mais de 18 meses podem apresentar pequena distância entre o solo e a copa, deve-se considerar a limitação ergonômica para a avaliação dessa variável, pois o operador deverá ficar agachado, sentado ou de cócoras.

A altura total das erveiras apresenta correlação significativa a $2 \%$ de probabilidade, com o número de troncos a $0,60 \mathrm{~m}$ de altura e inferiores a $1 \%$ para a mesma variável a $0,90 \mathrm{~m}$. Já a correlação com número de troncos $0,30 \mathrm{~m}$ não foi significativa (Tabela 2).

A área basal, obtida pela medida da circunferência da base do tronco (g0), apresenta correlação com a altura total $(r=0,31)$ semelhantes às obtidas por Fossati (1997) que observou $r=0,37$. As correlações entre altura de avaliação e área basal são crescentes com o aumento da primeira e mostram que a área basal dos troncos a 0,60 m de altura (g6) apresentam correlação e significância semelhantes aos obtidos a 0,90 m de altura $(\mathrm{g} 9)$.

As correlações do diâmetro médio da copa (DMC) com o número de troncos aumentam com a altura. Já a correlação entre DMC e a área basal ao nível do solo $(\mathrm{r}=0,41)$ é inferior à observada por Fossati (1997) que foi de $r=0,50$. A área basal dos troncos a 0,60 $\mathrm{m}$ de altura é a que apresenta maior correlação com o DMC, atingindo um $r=0,78$.

TABELA 2: Matriz de correlações lineares e suas probabilidades para as variáveis biométricas da copa, do tronco e biomassas da copa (avaliação preliminar de 70 árvores).

TABLE 2: Matrix of linear correlations and their probabilities for the biometric attributes of crown, trunk, and crown biomass (preliminary evaluation of 70 trees).

\begin{tabular}{cccc|c|c|c|c|c|c|c|c|c}
\hline Variáveis & ht & DMC & Nt3 & Nt6 & Nt9 & g0 & g3 & g6 & g9 & BC & PM \\
\hline ht & 1 & 0,67 & 0,17 & 0,28 & 0,55 & 0,31 & 0,68 & 0,78 & 0,79 & 0,79 & 0,84 \\
DMC & $\mathbf{0 , 0 0}$ & 1 & 0,29 & 0,41 & 0,69 & 0,41 & 0,69 & 0,78 & 0,75 & 0,89 & 0,82 \\
Nt3 & $\mathbf{0 , 1 7}$ & $\mathbf{0 , 0 2}$ & 1 & 0,58 & 0,50 & 0,57 & 0,34 & 0,28 & 0,24 & 0,33 & 0,29 \\
Nt6 & $\mathbf{0 , 0 2}$ & $\mathbf{0 , 0 0}$ & $\mathbf{0 , 0 0}$ & 1 & 0,66 & 0,33 & 0,56 & 0,59 & 0,43 & 0,50 & 0,48 \\
Nt9 & $\mathbf{0 , 0 0}$ & $\mathbf{0 , 0 0}$ & $\mathbf{0 , 0 0}$ & $\mathbf{0 , 0 0}$ & 1 & 0,42 & 0,68 & 0,70 & 0,74 & 0,69 & 0,70 \\
g0 & $\mathbf{0 , 0 1}$ & $\mathbf{0 , 0 0}$ & $\mathbf{0 , 0 0}$ & $\mathbf{0 , 0 0}$ & $\mathbf{0 , 0 0}$ & 1 & 0,36 & 0,33 & 0,38 & 0,41 & 0,41 \\
g3 & $\mathbf{0 , 0 0}$ & $\mathbf{0 , 0 0}$ & $\mathbf{0 , 0 0}$ & $\mathbf{0 , 0 0}$ & $\mathbf{0 , 0 0}$ & $\mathbf{0 , 0 0}$ & 1 & 0,89 & 0,82 & 0,84 & 0,85 \\
g6 & $\mathbf{0 , 0 0}$ & $\mathbf{0 , 0 0}$ & $\mathbf{0 , 0 2}$ & $\mathbf{0 , 0 0}$ & $\mathbf{0 , 0 0}$ & $\mathbf{0 , 0 1}$ & $\mathbf{0 , 0 0}$ & 1 & 0,87 & 0,89 & 0,91 \\
g9 & $\mathbf{0 , 0 0}$ & $\mathbf{0 , 0 0}$ & $\mathbf{0 , 0 5}$ & $\mathbf{0 , 0 0}$ & $\mathbf{0 , 0 0}$ & $\mathbf{0 , 0 1}$ & $\mathbf{0 , 0 0}$ & $\mathbf{0 , 0 0}$ & 1 & 0,86 & 0,89 \\
BC & $\mathbf{0 , 0 0}$ & $\mathbf{0 , 0 0}$ & $\mathbf{0 , 0 1}$ & $\mathbf{0 , 0 0}$ & $\mathbf{0 , 0 0}$ & $\mathbf{0 , 0 0}$ & $\mathbf{0 , 0 0}$ & $\mathbf{0 , 0 0}$ & $\mathbf{0 , 0 0}$ & 1 & 0,93 \\
PM & $\mathbf{0 , 0 0}$ & $\mathbf{0 , 0 0}$ & $\mathbf{0 , 0 1}$ & $\mathbf{0 , 0 0}$ & $\mathbf{0 , 0 0}$ & $\mathbf{0 , 0 0}$ & $\mathbf{0 , 0 0}$ & $\mathbf{0 , 0 0}$ & $\mathbf{0 , 0 0}$ & $\mathbf{0 , 0 0}$ & 1 \\
\hline
\end{tabular}

Em que: Valores em itálico-negrito representam as probabilidades; ht = Altura total; DMC = Diâmetro médio copa; $\mathrm{Nt} 3$ $=$ Número de troncos a $0,3 \mathrm{~m}$ de altura do solo; $\mathrm{Nt} 6=$ Número de troncos a $0,6 \mathrm{~m} ; \mathrm{Nt} 9=$ Número de troncos a $0,9 \mathrm{~m} ; \mathrm{g} 0$ = Área transversal do tronco a 0,0 m (nível do solo); g3 = Área transversal dos troncos a 0,3 m de altura do solo; g6 = Área transversal dos troncos a 0,6 m; g9 = Área transversal dos tronco a 0,9 m; BC $=$ Peso verde biomassa comercial; $\mathrm{PM}=$ Peso verde madeira da brotação (não-comercial).

As correlações do peso da biomassa comercial de erva-mate (BC) e do peso verde dos resíduos de madeira de brotação da copa (PM) com o número de troncos apresentam comportamento semelhante e são crescentes com a altura de avaliação. Já as correlações parciais dessas mesmas variáveis, depois de eliminados os efeitos das correlações lineares da altura total e do diâmetro médio da copa, mostraram comportamento diverso, como pode ser observado na Tabela 3, na qual se verifica que as correlações parciais do número de troncos $\mathrm{Nt} 3$ e $\mathrm{Nt} 9$ com o peso da biomassa da copa são significativos somente a 
probabilidades superiores a $2 \%$, e, nota-se, ainda, que o número de troncos contados a 0,60 m de altura apresenta correlações parciais altamente significativas com a biomassa.

As correlações das produções de biomassa da copa, BC e PM, com as seções transversais do tronco a diferentes alturas (g0, g3, g6, g9), apresentados na Tabela 2, mostram que os menores valores, para correlação, são observados quando se obtém a estimativa da área basal ao nível do solo, g0, sendo que seu valor é inferior à metade das correlações obtidas com as seções transversais a maiores alturas. A produção individual de biomassa da copa é fortemente correlacionada com o somatório das seções transversais dos troncos de cada erveira. Quando estas são avaliadas a 0,60 m de altura, as correlações atingem seu valor máximo para $\mathrm{BC}(\mathrm{r}=0,90)$ e para PM $(\mathrm{r}=0,89)$. Controlando os efeitos do DMC e da ht, na produção de BC e PM, verifica-se, na Tabela 3, que as correlações parciais entre a produção de biomassa e a área basal da base do tronco são desprezíveis e que estas são maiores para medições realizadas a $0,30 \mathrm{~m}$ de altura do tronco (g3), seguidas das medições a $0,60 \mathrm{~m}(\mathrm{~g} 6)$ e pela realizada aos $0,90 \mathrm{~m}$ de altura (g9).

TABELA 3: Correlações parciais e suas probabilidades entre as variáveis biométricas do tronco e biomassas da copa, com controle para altura total (ht) e diâmetro médio da copa (DMC) (avaliação preliminar de 70 árvores).

TABLE 3: Partial correlations and their probabilities between biometric attributes of trunk and crown biomass, with control for total height of the trees (ht) and average crown diameter (DMC) (preliminary evaluation of 70 trees).

\begin{tabular}{cccccccccccc}
\hline Pesos & Correlação/Probabilidade & $\mathrm{Nt3}$ & $\mathrm{Nt6}$ & $\mathrm{Nt} 9$ & $\mathrm{~g} 0$ & $\mathrm{~g} 3$ & $\mathrm{~g} 6$ & $\mathrm{~g} 9$ \\
\hline \multirow{2}{*}{$\mathrm{BC}$} & Correlação Parcial & 0,22 & 0,39 & 0,16 & 0,11 & 0,59 & 0,56 & 0,46 \\
& Probabilidade & $\mathbf{0 , 0 7}$ & $\mathbf{0 , 0 0}$ & $\mathbf{0 , 1 9}$ & $\mathbf{0 , 3 6}$ & $\mathbf{0 , 0 0}$ & $\mathbf{0 , 0 0}$ & $\mathbf{0 , 0 0}$ \\
\hline \multirow{2}{*}{ PM } & Correlação Parcial & 0,18 & 0,36 & 0,29 & 0,15 & 0,61 & 0,60 & 0,54 \\
& Probabilidade & $\mathbf{0 , 1 5}$ & $\mathbf{0 , 0 0}$ & $\mathbf{0 , 0 2}$ & $\mathbf{0 , 2 3}$ & $\mathbf{0 , 0 0}$ & $\mathbf{0 , 0 0}$ & $\mathbf{0 , 0 0}$ \\
\hline
\end{tabular}

Em que: $\mathrm{Nt} 3=$ Número de troncos a $0,3 \mathrm{~m} ; \mathrm{Nt} 6=$ Número de troncos a $0,6 \mathrm{~m} ; \mathrm{Nt} 9=$ Número de troncos a $0,9 \mathrm{~m} ; \mathrm{g} 0=$ Área transversal tronco a 0,0 m; g3 = Área transversal tronco a 0,3 m; g6 = Área transversal tronco a 0,6 m; g9 = Área transversal tronco a $0,9 \mathrm{~m} ; \mathrm{BC}=$ Peso verde biomassa comercial; $\mathrm{PM}=$ Peso verde madeira da brotação.

Os resultados encontrados permitiram observar que: a circunferência da base do tronco não deve ser utilizada para estimativas de produção, porque é pouco relacionada com tais produções e apresenta riscos na sua obtenção; a medição dos diâmetros a $0,30 \mathrm{~m}$ de altura também apresenta inconvenientes, como a baixa correlação do número de troncos com a produção de biomassa; comparando as alturas de medição a 0,60 m e a $0,90 \mathrm{~m}$, verifica-se que existe uma superioridade, em termos estatísticos, nas medições realizadas a 0,60 m de altura; o número de troncos a serem medidos a 0,60 e $0,90 \mathrm{~m}$ de altura é estatisticamente diferente. A $0,90 \mathrm{~m}$ ocorreu um incremento de mais de $50 \%$ no número de troncos, dificultando esta atividade; no manejo de erveiras, periodicamente, são necessárias podas de rebaixamento que, no caso em estudo, foram realizadas à altura aproximada de $0,80 \mathrm{~m}$.

Em virtude das razões expostas, decidiu-se realizar as avaliações do diâmetro dos troncos a 0,60 m de altura.

Pode-se, contudo, observar, na Tabela 2, que as correlações entre as áreas basais obtidas a 0,30; 0,60 e $0,90 \mathrm{~m}$ de altura apresentam elevada correlação linear entre si e que o número de troncos apresentam comportamento semelhante, indicando, com isso, ser possível desenvolver modelos para estimativa da g6 e do respectivo número de troncos partindo de medições realizadas a qualquer altura do intervalo 0,30 - 0,90 $\mathrm{m}$ de altura. Para desenvolver o modelo em questão, calcularam-se os coeficientes angulares da reta obtida da relação com intercepto zero de $\mathrm{g} 6=\mathrm{f}(\mathrm{g} 3)$ e f ( $\mathrm{g} 9)$, obtendo-se as estatísticas apresentadas na Tabela 4.

Estimou-se nova reta com esses coeficientes e coeficiente igual à unidade para a altura a $0,6 \mathrm{~m}$. Como resultado, obteve-se a seguinte função:

$$
\text { g6 }=(0,710065+0,468858 \text {. i }) \cdot g i \text {, }
$$

Em que: gi = a área basal à altura “i”, em metros, sendo que "ii” varia de 0,3 a 0,9 m.

Deve-se salientar, contudo, que esse modelo, bem como os da Tabela 4, devem ser usados com parcimônia, pois apresentam erro-padrão da estimativa (Sxy\%) superior a $20 \%$.

Ciência Florestal, v. 13, n. 1, 2003 
TABELA 4: Estatísticas dos modelos lineares para estimativa da área basal g6 em função de g3 ou g9. TABLE 4: Statistics of the linear models used to estimate the basal area $\mathrm{g} 6$ as a function of $\mathrm{g} 3 \mathrm{or} \mathrm{g} 9$.

\begin{tabular}{lcccc}
\hline Modelo & Coeficiente a & $\mathrm{R}^{2}$ (ajust) & $\mathrm{DW}$ & Syx\% \\
\hline $\mathrm{g} 6=\mathrm{a} \cdot \mathrm{g} 3$ & 0,846413 & 0,965 & 1,85 & 20,5 \\
$\mathrm{~g} 6=\mathrm{a} \cdot \mathrm{g} 9$ & 1,127728 & 0,944 & 1,84 & 26,1 \\
\hline
\end{tabular}

Em que: $\mathrm{R}^{2}$ (ajust) = coeficiente de determinação ajustado; DW = teste de Durbin-Watson; Syx\% = erro-padrão em percentagem da média.

\section{Efeitos do espaçamento entre plantas no número de troncos e na área basal dos troncos}

Essa análise foi conduzida em nível de planta e população para verificar a influência das distâncias nas entrelinhas (3, 4 e $5 \mathrm{~m}$ ) e nas linhas (2, 3 e $4 \mathrm{~m}$ entre plantas), sobre o número de troncos tomados a 0,6 m (Nt6) e sobre a área transversal dos troncos medidos a essa altura (g6). Os dados foram amostrados em dez plantas de cada tratamento e repetição, sendo os estimadores calculados pelas médias aritméticas. A referência para hectare foi obtida pela multiplicação do valor médio por planta pelo fator 10000 / (EL . E), onde EL e L são respectivamente a distância na entrelinha e na linha.

A área basal g6, quando analisada para o fator bloco (Tabela 5), mostrou um comportamento de similaridade entre os blocos 2 e 4 e os blocos 3 e 5 . O posicionamento dos blocos 2 e 4 , na parte superior do terreno, onde os solos são mais rasos, mostra a influência do local na área basal por planta e por hectare. Já o número de troncos por planta, $\mathrm{Nt6}$, apresentou comportamento inverso, pois os blocos 3 e 4 apresentam grande similaridade. O número de troncos por hectare, $\mathrm{Nt} \mathrm{ha}^{-1}$, não apresentou diferença significativa. Este comportamento dos blocos associado ao acerto na escolha para formar os grupos de poda, ficou evidenciado no resultado obtido, quando se comparou g6 e Nt6, em função do fator idade de brotação (24 e 28 meses), pois não foi observada diferença significativa a probabilidades superiores a $5 \%$.

O efeito da distância nas entrelinhas, na g6, por planta, mostrou-se significativo à probabilidade de 2,5\%, sendo que, na distância de $3 \mathrm{~m}$ g6, é menor e difere das g6 de 4 e $5 \mathrm{~m}$ de distância. Essas últimas, contudo, não apresentam diferença significativa. Desse comportamento, pode-se inferir que as plantas que vegetam com distância nas entrelinhas de 3 metros estão submetidas a maior efeito de competição, do que aquelas que vegetam com distância nas entrelinhas de 4 e $5 \mathrm{~m}$. Deve-se salientar que esse efeito de competição não é suficiente para determinar uma redução significativa na área basal por hectare $\left(\mathrm{g} 6 \mathrm{ha}^{-1}\right)$, pois o valor decresce e diverge significativamente com o aumento da distância de entrelinha, como pode ser observado na Tabela 5 e na Figura 3. Esse mesmo fator de variação não produziu efeito significativo para o número de troncos (Nt6) por planta, mas seu efeito pode ser percebido no número total de troncos por hectare que apresentaram comportamento similar ao da $\mathrm{g} 6 \mathrm{ha}^{-1}$ para esse mesmo fator de variação, ou seja, o número de troncos por hectare aumenta significativamente com a redução da distância na entrelinha.

Os efeitos provocados na área basal, g6, pela redução da distância entre plantas na linha denotam os níveis de competição em que essas plantas estão submetidas. Quando se amplia a distância de 2 para 3 m, e desta para $4 \mathrm{~m}$, a área basal incrementa de forma significativa, respectivamente, de 0,0094 $\mathrm{m}^{2}$ para 0,0130 $\mathrm{m}^{2}$ e desta para $0,0146 \mathrm{~m}^{2}$ por planta. Observa-se, na Tabela 5, que as entrelinhas promoveram comportamento similar, pois as erveiras incrementaram sua área basal g6 com o aumento da distância na entrelinha atingindo um máximo a $4 \mathrm{~m}$. Nota-se, na Figura 3, que esses incrementos são maiores nas distâncias mais amplas. Considerando o comportamento de g6 ha ${ }^{-1}$, em uma análise conjunta das distâncias de entrelinha e linha, verifica-se que $\mathrm{g} 6 \mathrm{ha}^{-1}$ é máxima em $2 \mathrm{~m}$ de distância na linha e não difere em nível de $5 \%$ de probabilidade da de $3 \mathrm{~m}$, mas esta, contudo, difere da de $4 \mathrm{~m}$ tanto na distância na linha como na entrelinha que também é significativamente diferente da distância de $5 \mathrm{~m}$ na entrelinha. Esse comportamento médio indicou que os espaçamentos com $2 \mathrm{~m}$ entre plantas atingiram o máximo da capacidade do sítio e muito próximo deste estão os espaçamentos com $3 \mathrm{~m}$ entre plantas. Deve-se salientar que as variáveis g6 e g6 ha ${ }^{-1}$ não apresentaram interação significativa entre as linhas e entrelinhas, e que essas interações só foram significativas para probabilidades superiores a $85 \%$.

Ciência Florestal, v. 13, n. 1, 2003 
TABELA 5: Teste de médias para os fatores bloco, idade, e distâncias nas entrelinhas e nas linhas, para as variáveis área basal e número de troncos por planta e por hectare.

TABLE 5: Multiple comparison test for the effects of block, tree age, distance between rows, and distance between trees within the rows on basal area and number of trunks per tree, and basal area and number of trunks per hectare.

\begin{tabular}{|c|c|c|c|c|}
\hline \multirow{2}{*}{$\begin{array}{l}\text { Fatores } \\
\text { Bloco } \\
\end{array}$} & \multicolumn{4}{|c|}{ Variáveis } \\
\hline & g6 / planta & Nt6 / planta & g6 ha ${ }^{-1}$ & Nt6 ha ${ }^{-1}$ \\
\hline 2 & $0,0116 \mathrm{a}$ & 8,5 & $10,31 \mathrm{ab}$ & 7874 \\
\hline 3 & $0,0127 \mathrm{ab}$ & 9,5 & 11,42 bc & 8777 \\
\hline 4 & $0,0112 \mathrm{a}$ & 9,4 & $9,61 \mathrm{a}$ & 8800 \\
\hline 5 & $0,0137 \quad b$ & 8,8 & $12,38 \quad \mathrm{c}$ & 8179 \\
\hline $\mathrm{F}($ Prob. $>\mathrm{F})$ & $3,57(0,0143)$ & $2,19(0,0883)$ & $5,34(0,0013)$ & $1,24(0,2967)$ \\
\hline \multicolumn{5}{|l|}{ Idade } \\
\hline 24 & 0,0121 & 9,0 & 10,87 & 8326 \\
\hline 28 & 0,0125 & 9,1 & 10,99 & 8490 \\
\hline $\mathrm{F}($ Prob. $>\mathrm{F})$ & $0,28(0,6039)$ & $0,12(0,7333)$ & $0,06(0,8161)$ & $0,16(0,6949)$ \\
\hline \multicolumn{5}{|l|}{ Entrelinhas (EL) } \\
\hline 3 & $0,0112 \mathrm{a}$ & 9,2 & $12,91 \quad \mathrm{c}$ & $10921 \quad \mathrm{c}$ \\
\hline 4 & $0,0128 \quad b$ & 9,0 & $10,96 \mathrm{~b}$ & 7996 b \\
\hline 5 & $0,0129 \mathrm{~b}$ & 8,9 & $8,88 \mathrm{a}$ & $6271 \mathrm{a}$ \\
\hline$\underline{F(\text { Prob. }>F)}$ & $3,73(0,0250)$ & $0,35(0,7053)$ & $21,63(0,0000)$ & $78,68(0,0000)$ \\
\hline \multicolumn{5}{|l|}{ Linhas (L) } \\
\hline 2 & 0,0094 a & $8,0 \mathrm{a}$ & $12,17 \quad b$ & $10596 \mathrm{c}$ \\
\hline 3 & $0,0130 \quad b$ & $9,4 \quad b$ & $11,16 \mathrm{~b}$ & 8187 b \\
\hline 4 & $0,0146 \quad \mathrm{c}$ & $9,8 \quad b$ & $9,42 \mathrm{a}$ & $6388 \mathrm{a}$ \\
\hline $\mathrm{F}($ Prob. $>\mathrm{F})$ & $29,47(0,0000)$ & $10,99(0,0000)$ & $10,48(0,0000)$ & $63,80(0,0000)$ \\
\hline Interação (EL x L) & $0,28(0,8926)$ & $0,35(0,8418)$ & $0,34(0.8495)$ & $2,65(0,0330)$ \\
\hline Média & 0,0123 & 9,1 & 10,93 & 8408 \\
\hline
\end{tabular}

Em que: Médias seguidas por letras iguais não diferem significativamente entre si pelo teste LSD a 5\% de probabilidade; F (sig) = razão F e sua significância; $\mathrm{g} 6$ = área basal a $0,60 \mathrm{~m}$ de altura; $\mathrm{Nt} 6$ = número de troncos a 0,60 $\mathrm{m}$ de altura; EL e L = respectivamente, distância na entrelinha e na linha, em metros.

O número de troncos por planta Nt6 não varia significativamente com a mudança da distância da entrelinha, mas a diferença da linha de $2 \mathrm{~m}$ para a de 3 ou $4 \mathrm{~m}$ é altamente significativa, como se pode observar na Tabela 5 e Figura 4. Esse comportamento faz com que não ocorra interação significativa entre as variáveis de espaçamento.

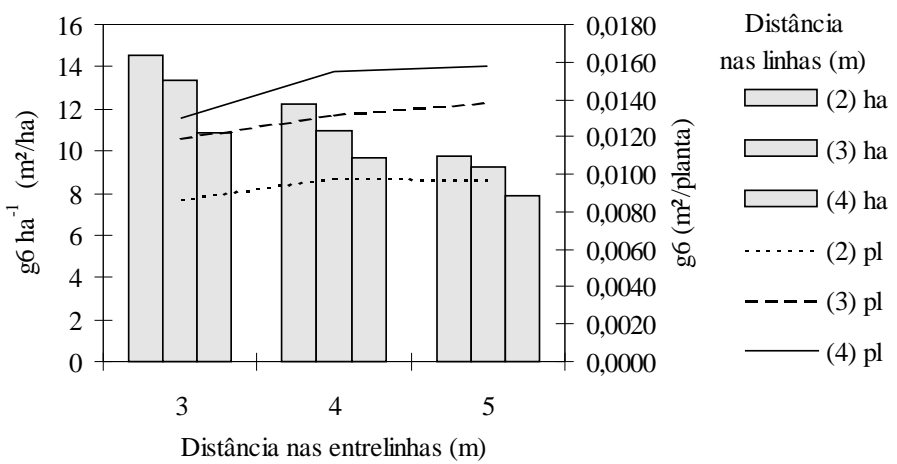

FIGURA 3: Área basal média por planta e hectare em função da distância entre plantas nas linhas e nas entrelinhas.

FIGURE 3: Basal area per tree and per hectare as a function of distance between rows and between trees within the rows. 
O número de troncos por hectare, por outro lado, reduz significativamente com o aumento das distâncias na linha e na entrelinha. A interação significativa (Prob. = 0,033), observada para linha e entrelinha, deve-se ao comportamento que pode ser visualizado na Figura 4, em que a proporcionalidade do Nt6 ha ${ }^{-1}$ é semelhante nas três entrelinhas, ou seja, a diferença absoluta de Nt6 ha ${ }^{-1}$ em função da distância dentro da linha, reduz com o aumento da distância da entrelinha.

A relativa constância do número de troncos por planta e a ampla variação da área basal g6 desses mesmos troncos com a redução da distância entre plantas sugere a existência de influências da competição entre plantas na relação do número de troncos Nt6 e da respectiva área basal g6.

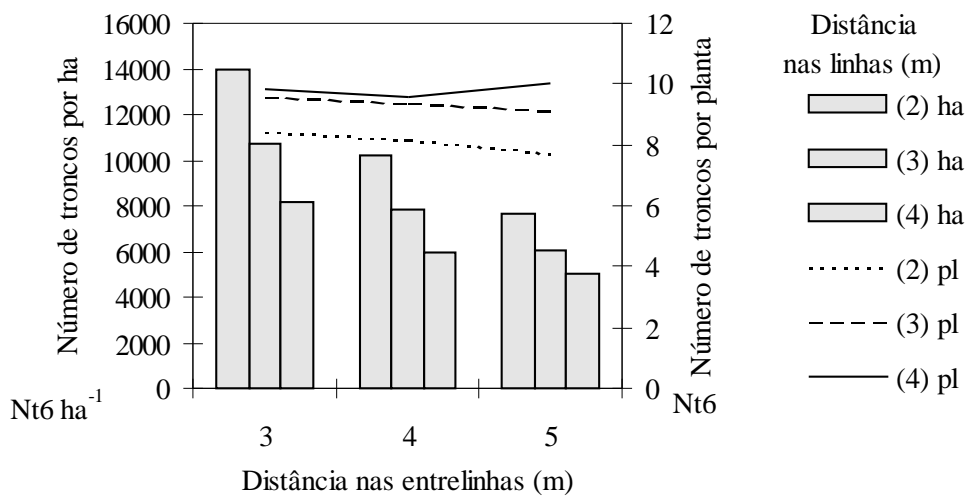

FIGURA 4: Número de troncos a 0,6 m de altura, por planta (Nt6) e por hectare $\left(\mathrm{Nt}^{6} \mathrm{ha}^{-1}\right)$ em função das distâncias nas entrelinhas e nas linhas.

FIGURE 4: Number of trunks at the height of $0.6 \mathrm{~m}$ per tree (Nt6) and per hectare (Nt6 ha $\left.{ }^{-1}\right)$ as a function of distance between rows and between trees within the rows.

\section{Efeitos do espaçamento entre plantas na morfometria das erveiras}

As variáveis clássicas utilizadas para descrever a copa, geralmente, referem-se ao seu comprimento (Cc) e ao seu diâmetro médio (Dc8) que apresentam, nas erveiras analisadas, valores e comportamentos muito semelhantes quanto à influência do fator bloco, destacando-se o bloco 5 como significativamente divergente. Esse comportamento já estava também evidenciado na variável g6 (Tabela 5) que apresenta diferença significativa mais ampla entre os blocos 4 e 5. Deve-se destacar que o valor médio de Dc8 e Cc são respectivamente 2,2 m e 2,4 m para os blocos 4 e 5. Quando avaliados em função da idade, verifica-se, contudo, uma diferença significativa para esse fator no diâmetro da copa (Dc8). O comportamento pode estar indicando que essa variável apresenta uma influência significativa da idade. Em termos absolutos, essa diferença é de somente duas unidades mínimas de medição de $0,1 \mathrm{~m}$, atingindo, em termos relativos, menos de10\% (Tabela 6).

A altura total (ht) das erveiras, como já era esperado, apresenta comportamento muito semelhante ao comprimento da copa $(\mathrm{Cc})$, não havendo diferença para tais variáveis nas duas idades de brotação da copa avaliadas, 24 e 28 meses. Em valores absolutos, a diferença entre as médias é de somente uma unidade de avaliação, ou seja, $10 \mathrm{~cm}$ em ambas as variáveis.

O espaçamento de linhas e entrelinhas altera significativamente ht e Cc. Na entrelinha de $3 \mathrm{~m}$, o Cc apresenta 2,1 m e diverge das com 4 e $5 \mathrm{~m}$ de entrelinha que apresentam 2,3 m. Quando a distância na linha aumenta de $2 \mathrm{~m}$ para 3 e $4 \mathrm{~m}$, o comprimento da copa também incrementa significativamente de 2,1 para 2,3 e 2,4 $\mathrm{m}$ respectivamente. Com muita similaridade, as médias da altura total em função das entrelinhas variaram de 3,0 $\mathrm{m}$ de ht na distância de $3 \mathrm{~m}$ e 3,1 para as de 4 e $5 \mathrm{~m}$.

O efeito da distância nas linhas é altamente significativo na ht, como pode ser observado na Tabela 6, fazendo com que o incremento de apenas uma unidade mínima de avaliação de $10 \mathrm{~cm}$ leve à divergência duas médias na comparação pelo teste LSD, no qual as distâncias de 2, 3 e $4 \mathrm{~m}$ nas linhas geraram alturas totais, respectivamente, de 2,9; 3,1 e 3,2 m. Disso, pode-se inferir, nas condições estudadas, que o 
crescimento em altura é, em média, mais influenciado pelos recursos do solo e água que pela competição por luz, pois, com a ampliação do espaçamento, a altura total tem tendência crescente.

TABELA 6: Teste de médias para os fatores bloco, idade de poda e distâncias nas entrelinhas e nas linhas, para as variáveis altura total (ht), comprimento da copa (Cc) e diâmetro médio da copa (Dc8).

TABLE 6: Multiple range test for the effects of block, time of pruning, distance between rows, and distance between trees within the rows on total height of the trees (ht), crown length (Cc), and average crown diameter (Dc8).

\begin{tabular}{lccc}
\hline Fatores & \multicolumn{3}{c}{ Variáveis } \\
\hline Bloco & Dc8 & Cc & ht \\
\hline 2 & $2,1 \mathrm{a}$ & $2,2 \mathrm{a}$ & $3,0 \mathrm{a}$ \\
3 & $2,2 \mathrm{a}$ & $2,2 \mathrm{a}$ & $3,0 \mathrm{a}$ \\
4 & $2,2 \mathrm{a}$ & $2,2 \mathrm{a}$ & $3,0 \mathrm{a}$ \\
5 & $2,4 \mathrm{~b}$ & $2,4 \mathrm{~b}$ & $3,3 \mathrm{~b}$ \\
F (Prob.>F) & $10,22(0,0000)$ & $4,07(0,0073)$ & $5,49(0,0011)$ \\
\hline
\end{tabular}

Idade

\begin{tabular}{lccc}
\hline 24 & $2,1 \mathrm{a}$ & 2,2 & 3,0 \\
28 & $2,3 \mathrm{~b}$ & 2,3 & 3,1 \\
$\mathrm{~F}($ Prob.>F) & $17,03(0,0000)$ & $3,82(0,054)$ & $2,21(0,1381)$ \\
\hline
\end{tabular}

Entrelinhas (E)

\begin{tabular}{lccc}
\hline 3 & 2,2 & $2,1 \mathrm{a}$ & $3,0 \mathrm{a}$ \\
4 & 2,3 & $2,3 \mathrm{~b}$ & $3,1 \mathrm{~b}$ \\
5 & 2,3 & $2,3 \mathrm{~b}$ & $3,1 \mathrm{~b}$ \\
$\mathrm{~F}($ Prob.>F) & $0,81(0,4464)$ & $4,25(0,0150)$ & $4,05(0,0182)$
\end{tabular}

Linhas (L)

\begin{tabular}{lccc}
\hline 2 & $2,0 \mathrm{a}$ & $2,1 \mathrm{a}$ & $2,9 \mathrm{a}$ \\
3 & $2,3 \mathrm{~b}$ & $2,3 \mathrm{~b}$ & $3,1 \mathrm{~b}$ \\
4 & $2,4 \mathrm{c}$ & $2,4 \mathrm{~b}$ & $3,2 \mathrm{c}$ \\
$\mathrm{F}$ (Prob.>F) & $33,83(0,0000)$ & $12,73(0,0000)$ & $13,28(0,0000)$ \\
\hline Interação (E x L) & $0,48(0,7486)$ & $0,25(0,9117)$ & $0,18(0,9469)$ \\
\hline Média geral & 2,2 & 2,3 & 3,1 \\
\hline
\end{tabular}

Em que: Médias seguidas por letras iguais não diferem significativamente entre si pelo teste LSD a 5\% de probabilidade; $\mathrm{ht}=$ altura total; $\mathrm{Cc}=$ comprimento da copa; e Dc8 = diâmetro médio da copa considerando oito raios.

Com base em Cc, ht e Dc8, que são variáveis de mensuração da copa, foram calculadas outras características para descrição quantitativa da copa. A razão entre o comprimento da copa e a altura total permite obter o grau de copa $=(\mathrm{Cc} / \mathrm{ht})$, da razão entre o diâmetro médio da copa com a altura total, o grau de cobertura $=(\mathrm{Dc} 8 / \mathrm{ht})$ e da razão entre o diâmetro médio da copa e de seu comprimento, o formal de copa $=$ (Dc8/Cc). Essas novas variáveis descritivas da copa foram analisadas quanto ao efeito de blocos, idade da brotação e das distâncias nas linhas e entrelinhas (Tabela 7).

O grau de copa ou percentual de copa $(\mathrm{Cc} / \mathrm{ht})$, tradicionalmente relacionado e utilizado como indicador da vitalidade e produtividade de árvores na Europa, é largamente utilizado no manejo de florestas (Sterba, 1992). Em erveiras, esse conceito é limitado pela poda periódica, que leva a uma uniformização recorrente da copa, fazendo com que o conceito de liberação da copa, pela sua melhoria e crescimento em altura, fique sem sentido. Neste trabalho, a sua avaliação relaciona-se com o sentido de vitalidade; contudo, o grau de copa só apresenta diferença significativa para o fator linha, indicando que a distância de $2 \mathrm{~m}$ na linha apresenta, em média, erveiras com menor vitalidade, mas deve-se salientar que, em termos absolutos, a diferença é bastante reduzida.

O grau de cobertura (Dc8/ht), conceitualmente como o anterior, é limitado no sentido amplo pela poda periódica, mas, por outro lado, pode identificar se o diâmetro da copa é influenciado ou influencia no crescimento da altura total e, portanto, pode influir diretamente na produção de biomassa comercial. Notase, na Tabela 7, que existe um grau de cobertura significativamente divergente, indicando que os blocos $4 \mathrm{e}$ 
5, avaliados em janeiro, têm maior diâmetro para uma mesma altura, quando comparados com os avaliados em outubro, passando respectivamente de 0,717 para 0,755. Diferentemente do grau de copa, o grau de cobertura não apresentou diferença significativa para o fator linha. A distância de entrelinhas 3 e 5 m são significativamente diferentes, contudo, a de 4 m não é diferente delas. Deve-se salientar que não é possível estabelecer um comportamento lógico quanto à variação do grau de copa e do grau de cobertura quando varia a distância na linha e entrelinha.

O formal de copa (Dc8/Cc) não apresentou diferença entre blocos e distâncias na linha e entrelinha. Para o fator idade, verificou-se que, aos 24 meses, as copas das erveiras são ligeiramente mais longas que largas, e aos 28 meses as copas apresentam comportamento inverso, ou seja, mais curtas que largas, apresentando um fator próximo à unidade, isto é, em média, a copa das erveiras apresentam comprimento de copa proporcional ao diâmetro de copa. O ponto central da utilização desse fator está na relação de que, para um mesmo diâmetro de copa, árvores com os menores valores para o fator serão as mais produtivas. Segundo Sterba (1992), esse fator pode ser muito pouco modificado pelo desbaste e está muito mais relacionado ao genótipo.

TABELA 7: Teste de médias para os fatores bloco, idade de poda e distâncias nas entrelinhas e na linhas, para as variáveis grau de copa $=(\mathrm{Cc} / \mathrm{ht})$, grau de cobertura $=(\mathrm{Dc} 8 / \mathrm{ht})$; formal de copa $=$ (Dc8/Cc) e índice de espaço vital (Ac/g6).

TABLE 7: Multiple range test for the effects of block, time of pruning, distance between rows, and distance between trees within the rows on crown ratio $(\mathrm{Cc} / \mathrm{ht})$, degree of coverage $(\mathrm{Dc} 8 / \mathrm{ht})$, crown shape (Dc8/Cc), and vital space index (Ac/g6).

\begin{tabular}{|c|c|c|c|c|}
\hline Fatores & \multicolumn{4}{|c|}{ Variáveis } \\
\hline Bloco & $\mathrm{Cc} / \mathrm{ht}$ & Dc8/ht & $\mathrm{Dc} 8 / \mathrm{Cc}$ & Ac/g6 \\
\hline 2 & 0,722 & $0,706 \mathrm{a}$ & 0,982 & $338,19 \mathrm{ab}$ \\
\hline 3 & 0,736 & $0,727 \mathrm{ab}$ & 0,997 & $319,69 \mathrm{a}$ \\
\hline 4 & 0,741 & $0,760 \mathrm{~b}$ & 1,036 & $414,59 \mathrm{c}$ \\
\hline 5 & 0,739 & $0,750 \mathrm{~b}$ & 1,027 & $373,09 \mathrm{~b}$ \\
\hline $\mathrm{F}($ Prob. $>\mathrm{F})$ & $1,60(0,1895)$ & $3,59(0,0140)$ & $1,48(0,2206)$ & $10,92(0,0000)$ \\
\hline \multicolumn{5}{|l|}{ Idade } \\
\hline 24 & 0,729 & $0,717 \mathrm{a}$ & $0,990 \mathrm{a}$ & $328,94 \mathrm{a}$ \\
\hline 28 & 0,740 & $0,755 \mathrm{~b}$ & $1,032 \mathrm{~b}$ & $393,61 \mathrm{~b}$ \\
\hline $\mathrm{F}($ Prob. $>\mathrm{F})$ & $2,79(0,0956)$ & $9,13(0,0027)$ & $4,07(0,0444)$ & $25,98(0,0000)$ \\
\hline \multicolumn{5}{|l|}{ Entrelinhas $(\mathrm{E})$} \\
\hline 3 & 0,726 & $0,752 \mathrm{~b}$ & 1,041 & 374,58 \\
\hline 4 & 0,738 & $0,735 \mathrm{ab}$ & 1,006 & 349,08 \\
\hline 5 & 0,739 & $0,721 \mathrm{a}$ & 0,985 & 359,84 \\
\hline$F($ Prob.>F) & $1,43(0,2417)$ & $4,49(0,0118)$ & $2,51(0,0826)$ & $1,29(0,2767)$ \\
\hline \multicolumn{5}{|l|}{ Linhas $(\mathrm{L})$} \\
\hline 2 & $0,719 \mathrm{a}$ & 0,709 & 0,995 & 378,42 \\
\hline 3 & $0,746 \mathrm{~b}$ & 0,747 & 1,011 & 350,09 \\
\hline 4 & $0,738 \mathrm{~b}$ & 0,752 & 1,027 & 355,06 \\
\hline $\mathrm{F}($ Prob. $>\mathrm{F})$ & $5,49(0,0045)$ & $2,05(0,1299)$ & $0,75(0,4721)$ & $1,78(16,95)$ \\
\hline Interação (E x L) & $0,55(0,6986)$ & $1,26(0,2867)$ & $0,95(0,4378)$ & $0,101(0,9819)$ \\
\hline Média geral & 0,735 & 0,736 & 1,011 & 361,27 \\
\hline
\end{tabular}

Em que: Médias seguidas por letras iguais não diferem significativamente entre si pelo LSD a 5\% de probabilidade; ht = altura total; $\mathrm{Cc}=$ comprimento da copa; $\mathrm{Dc} 8$ = diâmetro médio da copa considerando oito raios; e Ac = área da copa.

O índice de espaço vital (Ac/g6) não é significativamente influenciado tanto pelo espaçamento das linhas como das entrelinhas. Esse comportamento demonstra que a redução de espaçamento limita o crescimento da área basal e reduz conseqüêntemente a área de projeção da copa. Nota-se, contudo, que, em menores espaçamento, tanto na linha como na entrelinha, o índice de espaço vital apresenta valores superiores, podendo indicar maior eficiência em virtude da competição. 
Influência do espaçamento e idade da brotação na morfometria de povoamentos de Ilex paraguariensis ... 87

Segundo Sterba (1992), quanto menor o índice de espaço vital médio de uma população, tanto maior será sua área basal e, provavelmente, sua produção volumétrica por hectare. Nota-se, na Tabela 7, que os menores valores para esse índice são observados nos espaçamentos intermediários de linha $(3 \mathrm{~m})$ e entrelinha $(4 \mathrm{~m})$. O comportamento preconizado pelo autor é altamente influenciado pelo bloco e idade. Observa-se ainda na mesma tabela que os sítios que produzem menor área basal, em uma mesma idade, ou seja, os blocos 2 e 4, são os que apresentam maior índice de espaço vital. Disso, pode-se inferir que aos 24 meses de idade da brotação a área basal ainda não expressou, em termos médios, todo seu potencial de copa.

\section{CONCLUSÕES}

Os resultados obtidos neste estudo permitem concluir que:

a) Erveiras com bifurcações na proximidade da base apresentam correlação não-significativa entre o perímetro da base do tronco e a biomassa da copa, e a altura ideal de avaliação dos diâmetros do tronco é a $0,60 \mathrm{~m}$ de altura em relação ao nível do solo.

b) Em razão das podas periódicas a que as erveiras são submetidas, o número de troncos avaliados incrementa com a altura de avaliação.

c) A área basal à altura de $0,6 \mathrm{~m}$ do solo $(\mathrm{g} 6)$ foi significativamente (Prob. $<0,05)$ influenciada pelos espaçamentos nas entrelinhas e nas linhas. A influência maior na planta deve-se à distância na linha, sendo que as maiores distâncias apresentam os maiores valores. Quando se considera a área basal por hectare (g6 $\mathrm{ha}^{-1}$ ), verifica-se que os valores observados nas distâncias de 2 e $3 \mathrm{~m}$ na linha são superiores e apresentam valores não divergentes estatisticamente.

d) $\mathrm{O}$ número de troncos à altura de $0,6 \mathrm{~m}(\mathrm{Nt} 6)$ da planta foi significativamente influenciado pela distância entre plantas na linha, na qual a de $2 \mathrm{~m}$ foi menor e divergente das demais. Já o número de troncos por hectare apresentou influência significativa das distâncias nas entrelinhas como nas linhas, reduzindo seu número quando as distâncias foram ampliadas.

e) Os espaçamentos entre erveiras influenciam as dimensões das copas, sendo o diâmetro da copa significativamente influenciado pelo espaçamento nas linhas, com superioridade para os maiores espaçamentos.

f) A altura total e comprimento da copa foram significativamente (Prob. $<0,05$ ) influenciados pelas distâncias na linha e na entrelinha. Na entrelinha de 3 metros, as erveiras apresentaram a menor altura e divergiram das com entrelinhas de 4 e $5 \mathrm{~m}$ e estas não divergiram entre si. As distâncias de 2,3 e $4 \mathrm{~m}$ na linha geraram altura total que diferiram entre si, com superioridade para a maior distância. $\mathrm{O}$ comprimento da copa na menor distância na linha $(2 \mathrm{~m})$ diferiu das com 3 e $4 \mathrm{~m}$ e estas não diferiram entre si.

g) $\mathrm{O}$ formal de copa e o índice de espaço vital não foram influenciados pelo espaçamento. $\mathrm{O}$ grau de copa apresentou influência para distância na linha, sendo a de $2 \mathrm{~m}$ divergente das de 3 e $4 \mathrm{~m}$, e estas não divergiram entre si. $\mathrm{O}$ grau de cobertura apresentou diferença significativa para entrelinhas, sendo a de $3 \mathrm{~m}$ diferente da de $5 \mathrm{~m}$, mas estas não diferiram da de $4 \mathrm{~m}$.

\section{AGRADECIMENTOS}

À Universidade do estado de Santa Catarina (UDESC), por oportunizar o afastamento total de minhas atividades, sem perda de remuneração, para a realização deste trabalho e ao convênio PICDT/CAPES/UDESC, pela concessão de bolsa de estudo.

Aos Engenheiros Florestais Sandro Vaccaro, Helio Tonini e Fábio Fleig Seidelles, pelo inestimável auxilio na coleta dos dados.

Aos proprietários da Vera Cruz Agromate Ltda, sobretudo ao Cláudio, ao Clovis e ao Valter Magnabosco, pelo apoio financeiro, receptividade e por permitirem a coleta dos dados em seus ervais.

\section{REFERÊNCIAS BIBLIOGRÁFICAS}

ASSMANN, E. The principles of forest yield study. New York: Pergamon Press, 1970. 506p. 
CANADELL, J.; RIBA, M.; ANDRÉS, P. Biomass equations for Quercus ilex L. in the Montseny Massif, Northeastern Spain. Forestry, v.61, n.2, p.137-147, 1988.

CROW, T.R.; LAIDLY, P.R. Alternative models for estimating woody plant biomass. Can. J. For. Res., v. 10, p. 367-370, 1980.

DEAN, T.J.; LONG, J.N. Variation in sapwood area-leaf area relation within two stands of Lodgpole Pine. Forest Science, v. 32, n. 3, p. 749-758, 1986.

DURLO, M.A.; DENARDI, L. Morfometria de Cabralea canjerana, em mata secundária nativa do Rio Grande do Sul. Ciência Florestal, v. 8, n. 1, p. 55-66, 1998.

FOSSATI, L.C. Avaliação do estado nutricional e da produtividade de erva-mate (Ilex paraguariensis St Hil.) em função do sítio e da dioicia. 1997. 107f. Dissertação (Mestrado em Engenharia Florestal) - Universidade Federal do Paraná, Curitiba, 1997.

LEITE, P.F.; KLEIN, R.M. Vegetação. In: MESQUITA, O. V. (Coord.) Geografia do Brasil: Região Sul. Rio de Janeiro: IBGE, 1990. v. 2., p. 113-150.

MÄKINEN, H. Effect of stand density on radial growth of branches of scots pine in southern and central Finland. Can. J. For. Res., v. 29, p. 1216-1224, 1999.

MATTHECK, C. Trees: the mechanical design. Berlin: Springer, 1991. 121p.

MOTTA, F.S.; BEIRSDORF, M.J.C.; GARCEZ, R.B. Zoneamento agrícola do Rio Grande do Sul e Santa Catarina: normas agro-climáticas. Pelotas: Ministério da Agricultura, 1971. 80p.

MUNARETO, N. Manejo de planta. In: CURSO DE CAPACITACION EN PRODUCION DE YERBA MATE, 1., 1992, Cerro Azul. Anais... Cerro Azul: INTA, Centro Regional Sul, Estacion Experimental Agropecuaria Cerro Azul, 1992. p. 35-36.

O'CONNELL, B.M.; KELTY, M.J. Crow architecture of understory and open-grown white pine (Pinus strobus L.) saplings. Tree Physiology, v. 14, p. 89-102, 1994.

PORTER, J.L. Modules, models and meristems in plant architecture. In: RUSSELL, G.; MARSHALL, B. ; JARVIS, P.G. Plant canopies: their growth, form and function. Cambridge: University Press, 1989. Cap. 8, p. 143-159.

PRAT KRICUN, S.D.; BELINGHERI, L.D. Disposicion, distanciamento y densidade de plantaciones de yerba mate (Ilex paraguariensis St Hil.). In: CURSO DE CAPACITACION EN PRODUCION DE YERBA MATE, 1., 1992. Cerro Azul. Anais... Cerro Azul: INTA, Centro Regional Sul, Estacion Experimental Agropecuaria Cerro Azul, 1992. p. 27-30.

SANTA CATARINA. Gabinete de Planejamento e Coordenação Geral. Subchefia de Estatística, Geografia e Informática. Atlas de Santa Catarina. Rio de Janeiro: Aerofoto Cruzeiro, 1986. 173p. Tab. Graf. Col.

SCHNEIDER, C.; PETRY, G. Aspectos da cultura da erva-mate na região de Erebango, município de Getúlio Vargas-RS, em propriedade da Empresa Hoppen, Petry e Cia Ltda. In: SEMINÁRIO SOBRE ATUALIDADES E PERSPECTIVAS FLORESTAIS: SILVICULTURA DA ERVA-MATE, 10., 1983, Curitiba. Anais... Curitiba: EMBRAPA, CNPF, 1985. p. 64-70. (Documentos, 15).

SPSS. SPSS for Windows: programa de computador. USA, 1996, Versão 7.5.1.

STERBA, H. Forstliche Ertragslehre. Wien: Universität für Bodenkultur, 1992. 160p. (Heft, 4).

WHITTAKER, R.H.; WOODWELL, G.M. Dimension and production relations of trees and shrubs in the Brookhaven forest. J. Ecology, v. 56, p. 1-25, 1968. 